\title{
The degradation of nucleic acids in, and the removal of breakdown products from the small intestines of steers
}

\author{
By A. B. MCALLAN \\ National Institute for Research in Dairying, Shinfield, Reading, RG2 $9 A T$
}

(Received 14 December 1979 - Accepted 28 January 1980)

I. Nucleic acids and breakdown products were estimated in digesta taken from different sites in the small intestines of slaughtered steers given different diets. Amounts passing different sites were compared using cellulose as a non-digestible marker. The validity of this marker was checked with chromic oxide in some experiments. In other experiments, nucleic acids or derivatives were infused into the proximal duodenum of steers receiving diets of approximately equal proportions of flaked maize and hay. The amounts disappearing during passage through the small intestine were estimated using polyethylene glycol (PEG) as a nonabsorbable marker.

2. In the slaughter experiments the amounts of nucleic acids entering the small intestine varied with the type of diet. RNA and DNA disappeared on average, to extents of $89 \%$ and $80 \%$ respectively between the abomasum and the terminal ileum, irrespective of the dięt. RNA disappearance occurred almost entirely in the proximal quarter of the small intestine, whereas that of DNA extended further along the tract.

3. Nucleic acid degradation in the upper small intestine was accompanied by the transient appearance of adenosine, guanosine and pyrimidine nucleosides. These products were in greatest concentration in digesta from the first quarter of the small intestine and had generally completely disappeared by the terminal ileum.

4. Of the different substances infused into the small intestine, free nucleic acids were removed to extents greater than $97 \%$, adenine, guanine and uracil had completely disappeared, thymine and xanthine to approximately $80 \%$ and $95 \%$ and hypoxanthine and cytosine to only $51 \%$ and $48 \%$ respectively. The nucleosides adenosine and cytidine were also completely removed in the small intestine but were replaced, in part, by the catabolic products inosine plus hypoxanthine or cytosine respectively. Other nucleosides were removed to approximately half the extent of the corresponding bases.

5. Serum and urine allantoin and uric acid levels were related to the amounts of purines entering the small intestines in free or bound form.

Amounts of nucleic acids entering the duodenum of ruminants depend on the diet given but in general vary between 15 and $35 \mathrm{~g} / \mathrm{kg}$ dry matter (DM) (Smith \& McAllan, I97I; McMeniman, 1975) of which RNA constitutes approximately $600-700 \mathrm{mg} / \mathrm{g}$ nucleic acids. Pancreatic ribonuclease $\left(E C_{3} . I_{.4 .22}\right)$ has been found to be particularly abundant in ruminants (Barnard, 1969) and it has been shown that both RNA and DNA are extensively degraded in the small intestines of sheep and calves (Ellis \& Bleichner, 1969; Smith \& McAllan, I97I; Coehlo da Silva, Seeley, Beever et al. 1972; Coehlo da Silva, Seeley, Thomson et al. 1972; Jackson et al. 1976). Enzymes which may be involved in the subsequent degradation of products after nuclease action in the ruminant small intestine have been reviewed (Armstrong \& Hutton, 1975) but little experimental information is available on the products of nucleic acid catabolism and their subsequent fate.

The present work was undertaken in an attempt to measure the production, and determine the fate of nucleic acid degradation products in the small intestines of steers.

\section{METHODS}

\section{Animals and diets}

Expt I. Twelve castrated male Friesian steers, aged 42-53 weeks and weighing I $70-240 \mathrm{~kg}$ were used. Eight were equipped with simple abomasal cannulas. Groups of three animals were each given one of the four diets (A, B, C or D) shown in Table $I$. The diets were given in two feeds/d at 08.00 and 17.00 hours for at least 3 weeks before the experiment. Paper 
Table I. Daily amounts $(\mathrm{kg})$ of the major components of the stall diets given to the steers at the time they weighed $182-203 \mathrm{~kg}$, together with total nitrogen and metabolizable energy (ME) contents

(For animals at different live weights these amounts were increased or decreased by approximately $12 \%$ for each $20 \mathrm{~kg}$ increment in live weight)

$\quad$ Component
Hay
Barley-straw pellets (50:50)
Flaked maize
Decorticated groundnut meal
Heated soya-bean meal
Dried lucerne
Total N (g/kg DM)
ME (MJ/kg DM)

\begin{tabular}{cccc}
\multicolumn{4}{c}{ Diet } \\
A & B & C & D \\
1.80 & 1.80 & - & - \\
- & - & 3.50 & - \\
1.86 & 1.56 & - & - \\
- & 0.42 & - & - \\
- & - & 0.50 & - \\
16 & - & - & 3.60 \\
11.3 & 10.3 & 24 & 30 \\
& & & 10.4
\end{tabular}

impregnated with chromic oxide was given to eight of the steers at a rate of $0.85 \mathrm{~g} \mathrm{Cr}_{2} \mathrm{O}_{3} / \mathrm{kg}$ DM intake for the 3-week period.

Expt 2. Three castrated male Friesian steers, aged 2I-46 weeks and weighing $75-150 \mathrm{~kg}$ were used. Each received a basal diet of flaked maize and hay (diet A, Table 1 ) for the duration of the experiment. The feeding schedule was as for Expt I. All animals were equipped with simple cannulas in the proximal duodenum and re-entrant cannulas in the terminal ileum (Smith \& McAllan, 1971).

\section{Sample collection}

Expt I. All the steers were slaughtered 3-4 h after the morning feed. Ten were killed by injecting an overdose of sodium pentobarbitone solution ( $100 \mathrm{mg} / \mathrm{kg}$ body-weight) and bled by severing the jugular vein. Two steers, one receiving diet B (Table I) and one receiving diet $\mathrm{D}$ (Table $\mathrm{I}$ ), were shot then bled as described previously.

In all animals the body cavity was opened and the intestines exposed. Visible areas of the small intestines were tied off with string at approximately $30 \mathrm{~cm}$ intervals to prevent mixing of digesta as much as possible. The intestines were then dissected carefully with further tying off as more became exposed. The small intestine was finally tied off and severed at the abomasal and ileo-caecal junctions. The whole was removed intact, laid on a flat surface and measured. Each was marked off into eight approximately equal lengths of about $3 \mathrm{~m}$. Double ligatures were applied at the marked divisions and the sections were severed. The tying-off strings were removed and the digesta from each section was carefully removed, weighed and stored for analysis. The amounts of digesta in different segments varied appreciably and some sections were completely empty of digesta. In these cases no attempt was made to redistribute digesta and some segment mean values for analytical results were derived from only two animals. Full details of intestinal length, digesta content and other parameters will be the subject of a subsequent publication.

Abomasal digesta samples were obtained from those animals with abomasal fistulas just before slaughter by removing the cap and allowing digesta to flow out. Ultrafiltrates of digesta were prepared according to the procedure of Gregory (1954).

Expt 2. Solutions $(50 \mathrm{ml})$ of nucleic acids or derivatives containing $0.45 \mathrm{~g}$ sodium chloride and $3 \mathrm{~g}$ polyethylene glycol (PEG) were injected, in a single dose, into the duodenum through the cannula approximately $3 \mathrm{~h}$ after the morning feed. Continuous collection of ileal digesta was made in successive samples between $\mathrm{r}$ and $3 \mathrm{~h}$ after the infusion. Super- 
natant fractions were prepared by centrifuging ileal digesta for $5 \mathrm{~min}$ at $30000 \mathrm{~g}$ at $4^{\circ}$. Ultrafiltrates were prepared as described previously.

In some instances urine samples were collected for periods of 6-7 h and in one instance, for $48 \mathrm{~h}$. Blood samples were taken from the jugular vein, heparinized and the separated plasma stored for analysis.

\section{Analytical methods}

PEG was estimated as described by Smith \& McAllan (I97I). Nucleic acids (RNA and DNA) were determined by the procedures of McAllan \& Smith (1969) and separation of derivatives by gel filtration as described by McAllan \& Smith (1973). Ion exchange chromatography was carried out according to Anderson \& Ladd (1962). Total phosphorus in wetashed digesta samples (Smith \& McAllan, 1966) and inorganic P in ultrafiltrates were determined by the procedures of Smith et al. (1978). $\mathrm{Cr}_{2} \mathrm{O}_{3}$ was estimated as described by Williams \& Smith (1974) and cellulose by that of McAllan \& Smith (1974). Uric acid was determined by the method of Morgenstern et al. (1966) and allantoin by that of Young \& Conway (1942).

\section{RESULTS}

\section{The validity of cellulose as an indigestible marker in the small intestine}

The passage of $\mathrm{Cr}_{2} \mathrm{O}_{3}$ through the small intestines of sheep is reported to follow closely that of the particulate fraction as marked by ${ }^{144} \mathrm{Ce}$ (Thill et al. 1978 ). It has also been observed that cellulose is only found in the particulate phase of digesta from the abomasum and duodenum of young steers (A. B. McAllan, unpublished observations). $\mathrm{Cr}_{2} \mathrm{O}_{3}$ has been shown to be completely recoverable after passage down the small intestines (MacRae \& Armstrong, I969) and when cellulose values were expressed relative to $\mathrm{Cr}_{2} \mathrm{O}_{3}$ values (Table 2) it can be seen that little or no loss of cellulose occurred in the small intestines of the steers. Although no direct study has been made of the association of nucleic acids with digesta phases in the small intestine, it has been found that RNA is almost completely associated with the particulate fraction of digesta moving from the reticulo-rumen into the omasum and from the omasum into the abomasum (R. H. Smith, J. N. Banks \& A. B. McAllan, unpublished observations). It was concluded that cellulose would be a suitable marker to use in the present experiments for all twelve steers. Values for the amounts of cellulose in digesta from the eight segments of the small intestines of the twelve steers are given in Table 3 .

\section{Expt I}

\section{Nucleic acid digestion in the small intestine}

Results for the concentrations of both RNA and DNA measured in steer duodenal digesta are shown in Table 4. The amounts of RNA and DNA entering the small intestines were similar to those reported by Smith \& McAllan (197I) for calves receiving similar diets. Abomasal concentrations of RNA and DNA varied from 640 and $380 \mathrm{mg} / \mathrm{kg}$ digesta respectively in animals receiving a low-nitrogen diet (diet A, Table I) to 1970 and $950 \mathrm{mg} / \mathrm{kg}$ digesta respectively in animals receiving a high- $\mathrm{N}$ diet (diet $\mathrm{D}$, Table $\mathrm{I}$ ). However, the pattern of disappearance of each individual nucleic acid was similar on all four diets. On average approximately $20 \%$ of the RNA measured in abomasal digesta had disappeared from segment I digesta, approximately $70 \%$ from segment 2 digesta and approximately $85 \%$ from segment 3 . Little or no further net disappearance occurred in the other segments of the small intestine. Final net disappearance of RNA between the abomasum and terminal ileum averaged $89 \%$. The rate of DNA disappearance down the small intestine appeared to be markedly slower than that of RNA. Approximately $10 \%$ of the DNA measured in abomasal digesta had disappeared from segment I digesta; approximately $35 \%$ from 


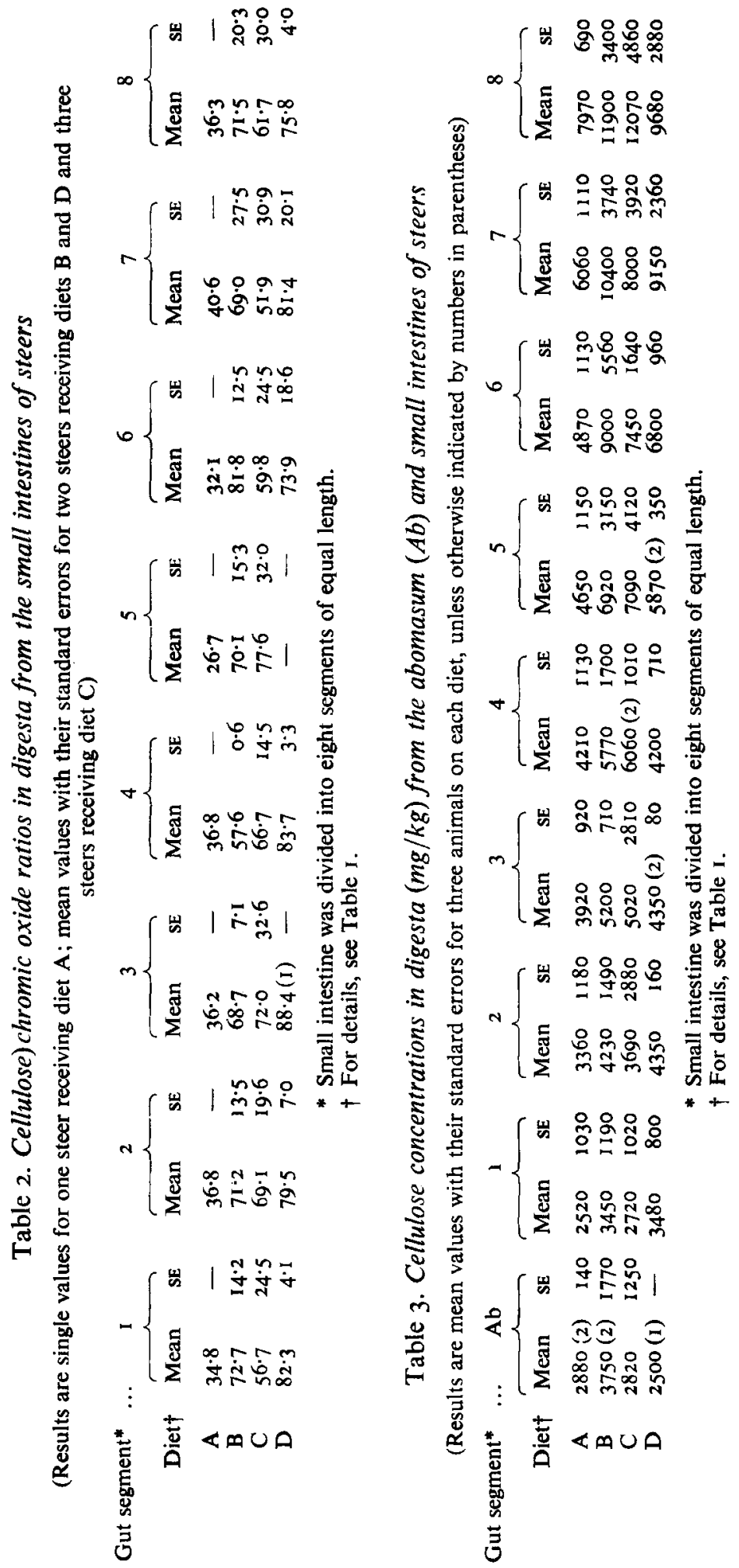




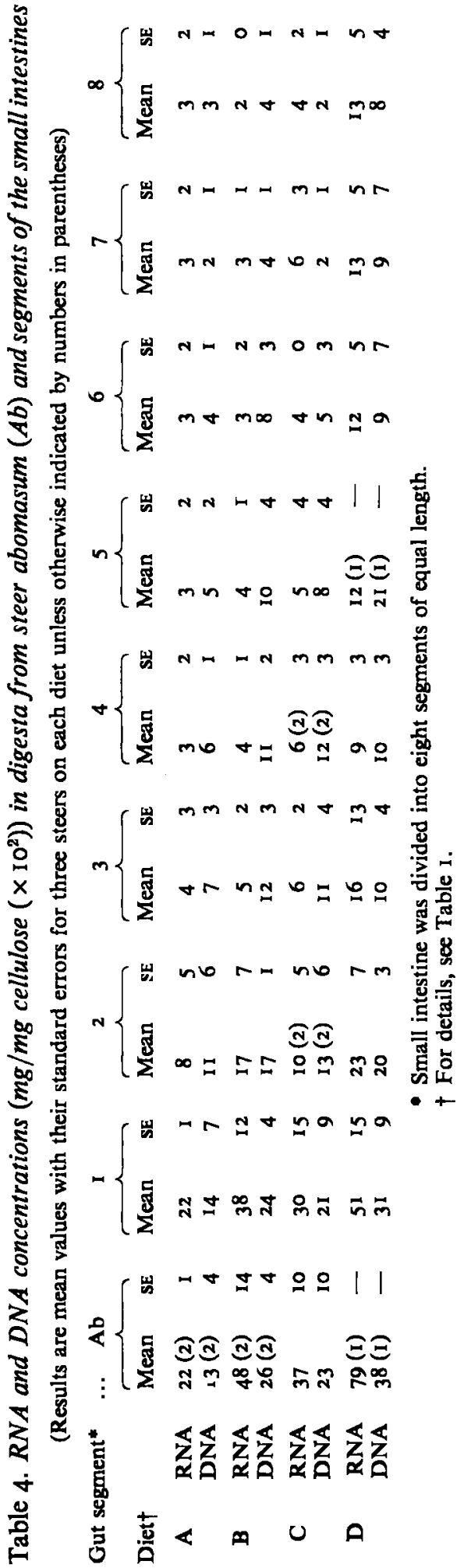




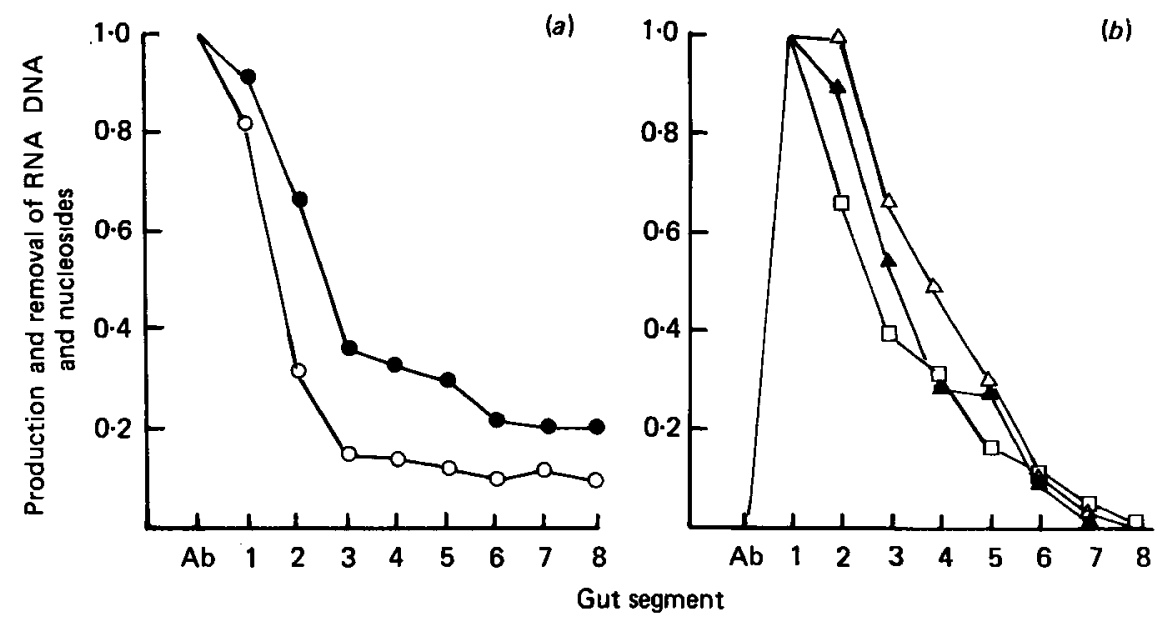

Fig. I. Patterns of removal of (a) RNA (O) and DNA (O) and the production and removal of $(b)$ adenine nucleosides $(\Delta)$, guanine nucleosides $(\Delta)$ and pyrimidine nucleosides $(\square)$ in the abomasum (Ab) and eight equal segments of the small intestines of steers. Results are mean values for twelve animals, except for abomasal samples which are mean values for eight animals, and are expressed as a proportion of that measured in the abomasum (RNA and DNA) or segment I digesta (nucleosides).

segment 2 digesta and approximately $65 \%$ from segment 3 digesta. Further disappearance continued in lower segments and over-all net disappearance of DNA between the abomasum and terminal ileum was approximately $80 \%$. No obvious differences were observed between results obtained with the two animals which had been shot compared with the others of their group and the values obtained from those animals are included in the means. Mean patterns of disappearance of nucleic acids in the small intestine are shown in Fig. I.

\section{Appearance and disappearance of nucleic acid derivatives}

Nucleotides. No free nucleotides were detected in digesta from any of the steers at any point between the abomasum and terminal ileum by the procedures used.

Nucleosides. No free nucleosides were detected in abomasal digesta from any of the steers. The purine nucleosides, adenosine and deoxyadenosine, appeared in appreciable amounts in the duodenal digesta of all animals on all diets (Table 5). Maximum concentrations were found in digesta from segment $I$ of animals receiving diets $A$ and $C$ (Table $I$ ) and in digesta from segment 2 of animals receiving diets $B$ and $D$ (Table 1 ). The nucleosides rapidly disappeared on passage of the digesta further down the tract (Table 5). They had completely disappeared from digesta in segment 8 of animals receiving diets $A, B$ or $C$, and were present in only trace amounts in the corresponding digesta of animals receiving diet $D$.

Guanosine and deoxyguanosine were present in the duodenal digesta to an even greater extent than the adenine nucleosides (Table 5). Segments in which maximum concentrations were observed and the extent and pattern of disappearance were very similar to those found for the adenine nucleosides (Table 5).

Quantitative separation of ribo- and deoxyribonucleosides was not possible by the techniques used in this work. However, it was confirmed by ion exchange chromatography that both guanosine and deoxyguanosine or adenosine and deoxyadenosine were present. Purine ribonucleosides were found to absorb ultraviolet light at $260 \mathrm{~nm}$ to virtually the same extent as the corresponding deoxyribonucleosides in the procedure used to estimate the content of the gel-filtration outflows and although the proportions of each may have varied 


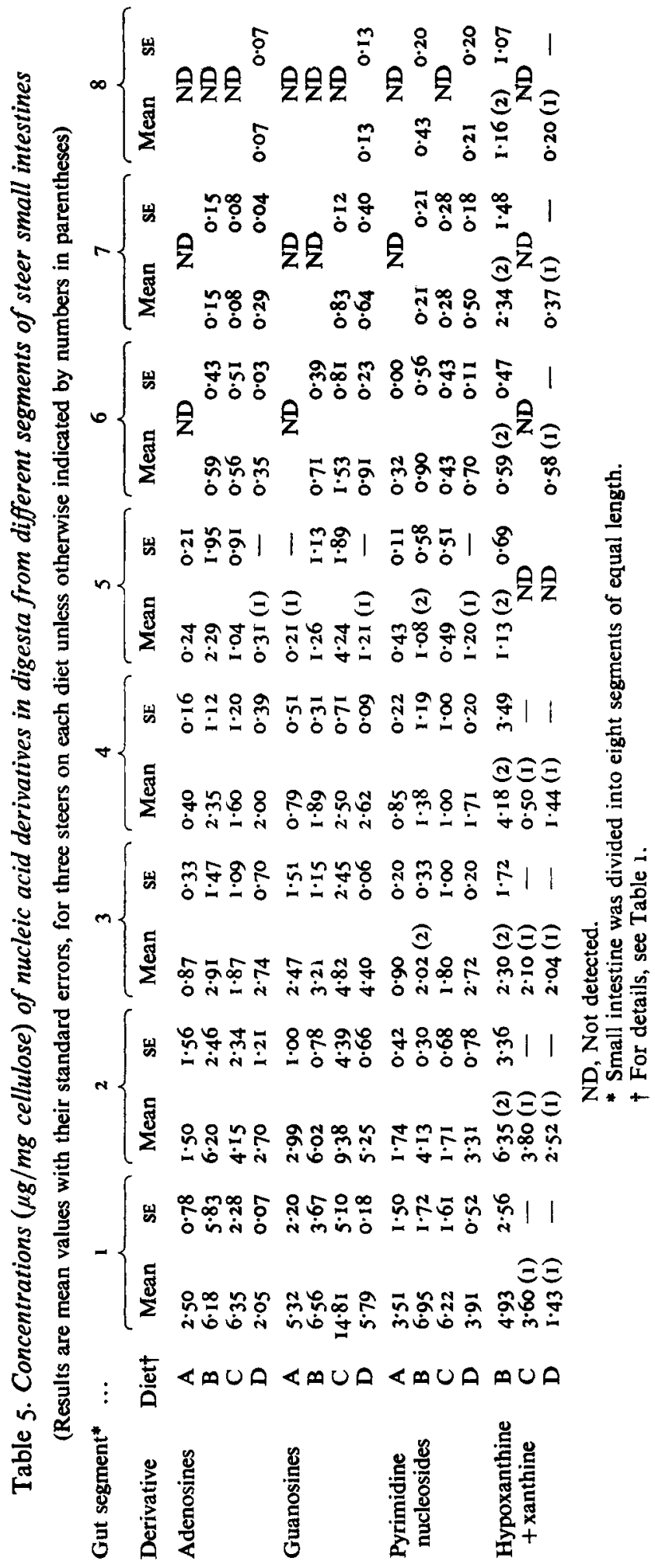


in digesta from different segments, this would have had only a very small effect on the estimates of the amounts present.

Calculations assuming an average digestion of $20 \%$ RNA and $10 \%$ DNA in segment I (Table 4) showed that the amounts of guanosine plus deoxyguanosine and adenosine plus deoxyadenosine measured in segment I digesta accounted for approximately 40 and $20 \%$ respectively of the theoretical amounts released up to that point. Similar calculations for digesta from segment 2 based on $70 \%$ RNA and $35 \%$ DNA degradation indicated that the amounts of guanine nucleosides and adenine nucleosides found accounted for approximately 10 and $5 \%$ respectively of the theoretical.

In order to make a quantitative estimate of the total pyrimidine nucleosides present, which were not separated from one another during gel filtration, it was assumed that equal amounts of thymidine, uridine, cytidine and deoxycytidine were present. The calculated absorbance of such a mixture was used for calibration. Results calculated in this way are shown in Table 5. The greatest concentrations were found in segment I digesta from all steers except those receiving diet $D$. These nucleosides disappeared from the digesta on passage down the gut and had virtually completely disappeared by segment 8 (Table 5).

Calculations of the possible production of pyrimidine nucleosides from average amounts of nucleic acids disappearing in segments $I$ and 2 indicated that the measured amounts found accounted for approximately I 26 and $26 \%$ respectively of the theoretical quantities. Subsequent ion exchange chromatographic examination of samples selected for high pyrimidine nucleoside contents showed variable proportions of the four nucleosides in digesta from segment $I$ of different animals. These proportions changed markedly during passage of digesta down the small intestine.

Proportional contributions of the individual pyrimidine nucleosides to the total amounts estimated in digesta from segment $I$ in four steers varied from 0.08 to 0.15 (thymidine), 0.35 to 0.55 (uracil) and 0.2 I to 0.46 (cytidine + deoxycytidine). However, the pyrimidine fraction in digesta from segment 6 of the same animals comprised approximately $90 \%$ cytidine + deoxycytidine.

Mean patterns of production and removal of nucleosides in the small intestine are shown in Fig. 1 .

Bases. No pyrimidine or amino purine bases were detected in digesta from any portion of the small intestine. The oxypurine bases xanthine and hypoxanthine were found in digesta from only four animals (Table 5). Patterns of accumulation and disappearance were similar to those of the amino purine nucleosides. The proportion of xanthine to hypoxanthine was, on average, approximately $2: \mathrm{I}$, similar to that between the amounts of guanine and adenine nucleosides found in digesta.

Other products. Digesta from four steers, each receiving a different diet (diets A, B, C or D, Table I) were examined for total P (TP) and inorganic P (IP). Typical results are shown in Table 6 for the steer receiving diet $C$. Organic $P(O P)$ was taken as the difference between TP and IP. Virtually identical patterns were found in digesta from the other three steers but the TP contents of digesta from segment I were 1340,1260 and $750 \mathrm{mg} / \mathrm{kg}$ digesta for steers receiving diets $A, B$ and $D$ respectively.

TP disappeared continuously down the small intestine (Table 6) and only approximately $20 \%$ of the total measured in segment I digesta survived to the terminal ileum. Approximately $30 \%$ of the TP disappeared between segments $I$ and 2 and, although IP contributed approximately $60 \%$ of TP, approximately equal amounts of IP and OP contributed to this loss. Approximately $50 \%$ of the OP disappeared between segments $I$ and 2 and there was apparently little further loss of OP further down the small intestine. On the other hand, IP disappeared continuously down the tract and had almost disappeared by segment 8 . No apparent increase was observed in IP in segment 2 digesta although appreciable amounts 
Table 6. Total, inorganic and organic phosphorus contents ( $\mathrm{mg} / \mathrm{kg}$ digesta) and P:cellulose values from different segments of the small intestine

(Results $\mathrm{mg} / \mathrm{I} 00 \mathrm{~g}$ digesta are for one steer receiving a flaked maize and hay diet (diet A, Table I))

\begin{tabular}{|c|c|c|c|c|c|c|c|c|}
\hline & & & & Gut se & gments* & & & \\
\hline & I & 2 & 3 & 4 & 5 & 6 & 7 & 8 \\
\hline Total P & 1130 & I I IO & 880 & 580 & 450 & 720 & 760 & 620 \\
\hline Total P:cellulose & 0.61 & 0.42 & 0.39 & 0.31 & 0.18 & 0.20 & 0.15 & 0.13 \\
\hline Inorganic $\mathbf{P}$ & 680 & 790 & 620 & 370 & 200 & 120 & 70 & 30 \\
\hline Inorganic P: cellulose & 0.37 & 0.30 & 0.27 & 0.20 & 0.08 & 0.03 & 0.01 & 0.01 \\
\hline Organic P & 450 & 320 & 260 & 210 & 250 & 500 & 690 & 590 \\
\hline Organic P:cellulose & 0.25 & 0.12 & 0.12 & 0.11 & 0.10 & 0.14 & 0.13 & 0.12 \\
\hline Inorganic P:total P & 0.60 & 0.71 & 0.70 & 0.64 & 0.44 & 0.17 & 0.09 & 0.05 \\
\hline
\end{tabular}

* Small intestine was divided into eight segments of equal length.

may have been released from nucleic acids digested therein. The proportion of $1 P$ relative to TP changed appreciably with passage of digesta down the gut (Table 6).

Allantoin and uric acid levels were also determined in small intestine digesta. There was no apparent increase in either of these purine breakdown products and both disappeared to extents of approximately $80 \%$ between the duodenum and terminal ileum. Concentrations ranged from 19.2 to 26.2 and 10 to $75 \mathrm{mg} / \mathrm{kg}$ for allantoin and uric acid respectively in digesta from segment $I$.

\section{Expt 2}

Mean ( \pm SE) amounts of RNA and DNA in duodenal digesta of three steers receiving diet $A$ (Table I) were $670 \pm 30$ and $350 \pm 60 \mathrm{mg} / \mathrm{kg}$ digesta respectively. The over-all disappearance between proximal duodenum and terminal ileum, based on PEG, was $84 \pm 6 \%$ and $78 \pm 8 \%$ for RNA and DNA respectively. Portions of 5 or $10 \mathrm{~g}$ yeast RNA or thymus DNA infused into the proximal duodenum had virtually completely disappeared in the small intestine. On correcting for digesta nucleic acid degradation it was calculated that both added nucleic acids were removed to the extent of at least $97 \%$. Small amounts of cytosine and hypoxanthine were found at the terminal ileum but the amounts measured accounted for less than $20 \%$ and $10 \%$ respectively of their theoretical yield from the infused dose of nucleic acids. These levels of nucleic acids ( 5 and $\mathrm{IOg}$ ) would supply approximately 3.5 and $7.0 \mathrm{mmol}$ respectively of individual nucleosides or bases. It was found to be impossible to investigate greater concentrations of nucleic acids because of the problems of solubility.

Infused amounts of between 7 and $20 \mathrm{mmol}$ of adenine, guanine or uracil completely disappeared in the small intestine (Table 7). Thymine and xanthine did not completely disappear with hypoxanthine and cytosine even more resistant (Table 7).

Apart from adenosine and cytidine, infused nucleosides were more resistant to removal than their corresponding bases and survived to varying extents to the terminal ileum (Table 7). Cytidine underwent some catabolism in the small intestine and from infusions of 10 and $20 \mathrm{mmol}, 20 \%$ and $53 \%$ respectively reached the terminal ileum in the form of cytosine. Adenosine also completely disappeared and was replaced, in part, by inosine and hypoxanthine in an approximate ratio of $2: \mathrm{I}$. The amounts of adenosine accountable for at the terminal ileum as inosine + hypoxanthine were $23 \%$ and $51 \%$ for infusions of 9 and $18 \mathrm{mmol}$ respectively. Inosine was quite resistant in the small intestine (Table 7 ) but underwent some catabolism and approximately $20 \%$ of infusions of 9 and $18 \mathrm{mmol}$ appeared at the ileum as hypoxanthine.

The infusions of nucleic acids or derivatives did not result in any consistent increased 
Table 7. Amounts (proportions of the doses infused into the proximal duodenum) of infused nucleic acid derivatives surviving transit of the small intestines of steers

(Results are mean values with their standard errors for two steers)

\begin{tabular}{|c|c|c|c|c|}
\hline & \multicolumn{4}{|c|}{ Dose infused (mmol) } \\
\hline & \multicolumn{2}{|c|}{$7-9$} & \multicolumn{2}{|c|}{$17-20$} \\
\hline & Mean & SE & Mean & SE \\
\hline Adenine & 0 & - & 0 & - \\
\hline Guanine & 0 & - & 0 & - \\
\hline Uracil & 0 & - & 0 & - \\
\hline Cytosine & 0.34 & 0.14 & 0.51 & 0.16 \\
\hline Xanthine & 0 & - & 0.05 & 0.05 \\
\hline Hypoxanthine & 0.14 & 0.05 & 0.48 & 0.13 \\
\hline Thymine & 0 & - & 0.20 & 0.09 \\
\hline Adenosine & 0 & - & 0 & - \\
\hline Guanosine & 0.20 & 0.08 & 0.39 & 0.11 \\
\hline Uridine & $0 \cdot 10$ & 0.03 & 0.45 & 0.16 \\
\hline Cytidine & 0 & - & 0 & - \\
\hline Xanthosine & 0.36 & 0.12 & 0.58 & 0.20 \\
\hline Inosine & 0.21 & 0.06 & 0.40 & 0.14 \\
\hline Thymidine & 0.16 & 0.06 & 0.23 & 0.08 \\
\hline
\end{tabular}

levels of allantoin or uric acid in digesta reaching the terminal ileum. Uric acid levels ranged from $0-70 \mu \mathrm{mol} / \mathrm{kg}$ digesta and allantoin levels averaged $141 \mu \mathrm{mol} / \mathrm{kg}$ digesta for three steers. Increases in blood plasma levels of these products were observed. Typical results are shown in Table 8. At $2 \mathrm{~h}$ after infusion of $17 \mathrm{mmol}$ adenine or guanine, plasma allantoin levels had increased by approximately $30 \%$ over pre-infusion levels. Increased plasma allantoin levels were also observed $2 \mathrm{~h}$ after infusing $17-20 \mathrm{mmol}$ of adenosine, guanosine, xanthosine, inosine, xanthine or hypoxanthine, ranging from $15-35 \%$ above the preinfusion level.

Uric acid levels in plasma were elevated to similar extents (Table 8). No increases in blood allantoin or uric acid levels were observed when PEG alone, or with pyrimidine derivatives, was infused. Similar results were obtained with other steers.

Urinary excretion of allantoin increased with duodenal infusion of nucleic acids or derivatives (Table 8). The excreted allantoin accounted for only approximately $18 \%$ of the theoretical possible but these urines were only collected over a $6-7 \mathrm{~h}$ period. Subsequent infusions with another steer, during which urine was collected over a $48 \mathrm{~h}$ period, showed that urinary allantoin excretion (in excess of endogenous excretion) accounted for $65 \%$ and $40 \%$ of the theoretical from $37 \mathrm{mmol}$ adenine or guanine respectively, infused into the duodenum. Increased uric acid secretions are shown in Table 8. Similar increases were observed in allantoin and uric acid secretions when $17-20 \mathrm{mmol}$ of adenosine, guanosine, xanthosine, inosine and xanthine were infused into the proximal duodenum.

\section{DISCUSSION}

The amounts of nucleic acids entering the small intestines of steers in the present experiments were similar to those obtained for calves receiving similar diets (Smith \& McAllan, 1971). The extent of degradation of the RNA and DNA (on average 89 and $80 \%$ respectively) were in the ranges $85-95 \%$ for RNA and $75-85 \%$ for DNA reported for calves (Smith \& McAllan, 1971) and sheep (Ellis \& Bleichner, 1969; Coehlo da Silva, Seeley, Beever et al. 1972; Coehlo da Silva, Seeley. Thomson et al. 1972). The position of sampling, 


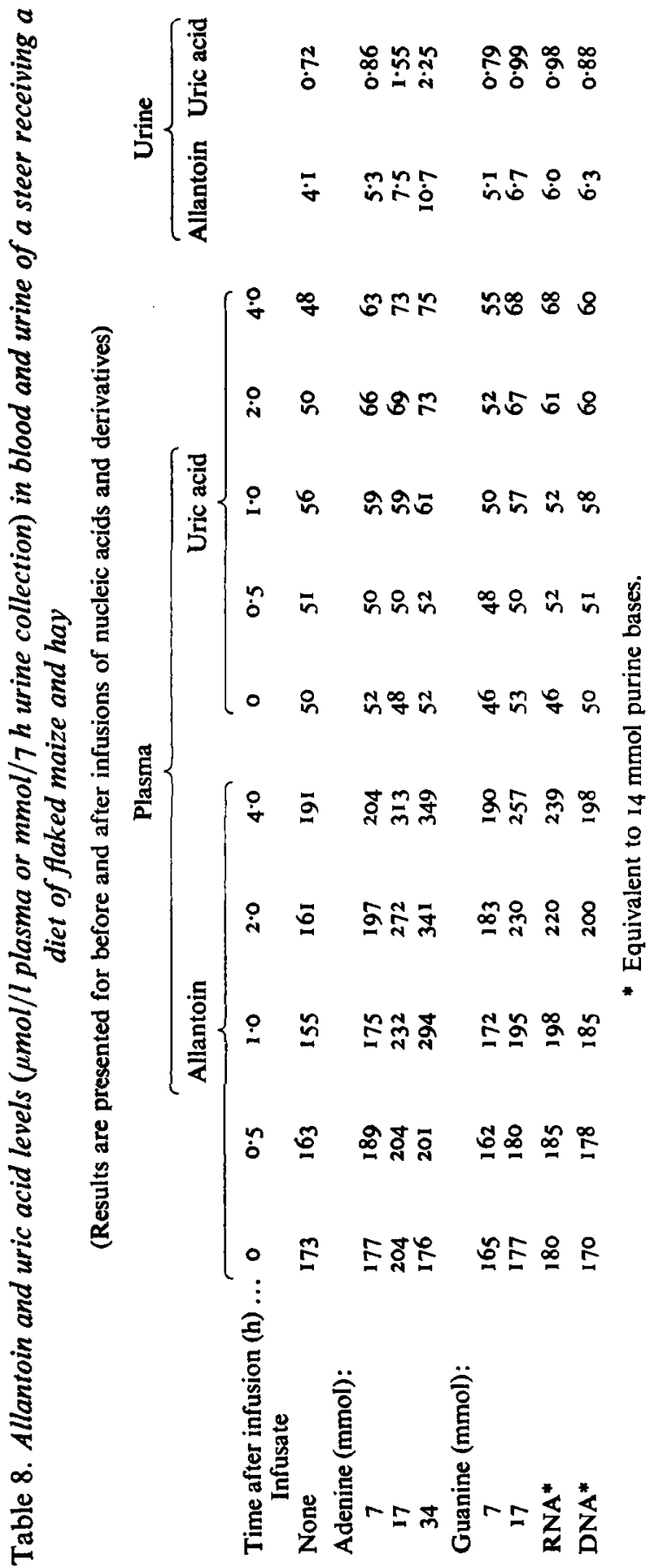


the presence of nucleases and the time of contact between substrate and enzyme would influence the initial concentration measured and could explain the variations observed by different groups of workers. There is also a constant desquamation of epithelial cells into the lumen of the small intestine which will contribute unknown amounts of nucleic acids. In the living animal these additions presumably occur throughout the length of the intestine and would represent a greater proportion of the total at the terminal ileum than the proximal duodenum. This would tend to lead to an underestimation of the disappearance of digesta nucleic acids. In the slaughtered animals however, the addition of epithelial nucleic acids may be greatest in the upper small intestine. Badawy et al. (I958) found marked shedding of the epithelium in the upper small intestine of sheep which had been shot and bled compared with drugged animals. However, in the present experiment, no obvious differences were observed in the nucleic acid contents of segment I digesta from the two animals which were shot compared with the other animals on the same diets which had been drugged. Most of the nucleic acid degradation occurred in the proximal duodenum as has already been shown for sheep (Jackson et al. 1976).

If an average digesta flow of approximately $25 \mathrm{~kg} / \mathrm{d}$ entering the duodenum is taken for the steers used in the present study (based on $\mathrm{Cr}_{2} \mathrm{O}_{3}$ estimations in Expt I), the daily flows of nucleic acids would range from $25-75 \mathrm{~g}$, depending on the diet.

It has been shown in Expt 2 that single doses of 5-I0 $\mathrm{g}$ of RNA or DNA/50 ml infused into the proximal duodenum were essentially completely digested. These concentrations were of the order of 50-100 times that normally present in digesta and it can be seen that the capacity for the degradation of nucleic acids in the small intestines of steers far exceeds the normal demands placed upon it. Similar extensive degradation of 'exogenous' nucleic acids introduced into the abomasum of lambs has been reported by Condon \& Hatfield (1971).

According to Armstrong \& Hutton (1975) nucleic acids entering the small intestines of ruminants would be degraded to nucleoside $3^{\prime}$ - and $5^{\prime}$-phosphates. In the present study little or no free nucleotides were detected in digesta from any part of the small intestine presumably because they were either absorbed or catabolized further. However, it was found that purine or pyrimidine nucleotides were not transported intact across the small intestines of rats or hamsters (Wilson \& Wilson, 1958; Wilson \& Wilson, I962). Assuming that mechanisms of absorption in ruminant small intestine are similar to those in single stomached animals, it seems unlikely that intact nucleotides would have been absorbed from the steer small intestines. Non-specific alkaline phosphatase (EC 3.1.3. I) which can remove phosphate attached to $\mathrm{C}-3^{\prime}$ in single nucleotides has been found in calf and sheep small intestines (Portmann, 1957; Toofanian \& Teshfam 1978). Specific 5'-nucleotidase $(E C$ 3.1.3.5) has also been isolated from calf small intestinal mucosa (Centar \& Behal, 1966) and it seems probable that nucleotides released during the degradation of nucleic acids undergo de-phosphorylation. However, although appreciable losses of OP were shown in these experiments, much of which was probably nucleic acid-P being released, losses in IP were also shown, even in the regions of maximum OP losses. This indicated that the IP concentrations measured were net values from production and absorption processes continuing at the same time and release of IP from nucleotides could not be shown. That the nucleotides are indeed de-phosphorylated was however shown by the accumulation of purine and pyrimidine nucleosides in digesta from the proximal duodenum.

These nucleosides and infused nucleosides were extensively removed from digesta passing down the small intestine. Whether this was by direct absorption or by catabolism to bases first, is not known. Some information on part of the process can be deduced from the results presented in this paper. The deamination of adenosine is not unexpected as the calf small intestine mucosa is a rich source of adenosine deaminase (EC 3.5.4.4) (Zittle, 1946). The resulting inosine however appears to be subjected to nucleoside phosphorylase 
$(E C 2.4 .2 .1)$ or nucleosidase $(E C$ 3.2.2.8) action producing hypoxanthine. It is unlikely that the hypoxanthine was produced by conversion of adenosine to adenine and subsequent deamination of the base otherwise deamination of infused adenine would similarly have resulted in the release of hypoxanthine but this was not observed.

The catabolism of cytidine is also rapid. Appreciable amounts appear to be subjected to nucleosidase action producing cytosine. Whether the rest of the cytidine is absorbed as such or deaminated to uracil before absorption is not known. Indirect evidence for the presence of cytidine deaminase ( $E C$ 3.5.4.5) in calf intestinal mucosa has been reported (Christman, 1952).

The present findings on the extent of removal of bases from the small intestines of steers confirms and extends the results of Condon (I971) and Condon et al. (1970) who found that adenine and uracil infused into the abomasum of lambs was completely removed in the small intestine. The apparent resistance of cytosine to catabolism or absorption has also been reported in sheep (Jackson et al. 1976).

Further catabolism of purine and pyrimidine bases or nucleosides may have occurred at the intestinal mucosa. No increases were observed in concentrations of uric acid or allantoin passing the terminal ileum during the infusion experiments, but they may have been produced and absorbed. It seems probable from the present study that the absorbable end products of nucleic acid degradation are nucleosides, bases or both. From the greater digestibilities of bases relative to nucleosides it might appear that the conversion of nucleoside to base may be a limiting step in an absorption process. However, the amounts of the various nucleosides actually disappearing during the infusion experiments were all, with the possible exception of cytosine, well above the quantities normally presented to the small intestine in digesta.

The relationships observed between purine (free or bound) concentrations in the rumen or entering the duodenum and allantoin or uric acid levels reported here and elsewhere for blood (Kaplan \& Pobirsky, 1974) and urine (Topps \& Elliott, 1965; McMeniman, 1975) indicate considerable breakdown and excretion of purine-N. The variations observed by the different groups on the extent of excretion of catabolism products may reflect the different states of $\mathrm{N}$ balance of the animals used and the varying importance of nucleic acid- $\mathrm{N}$ under these conditions.

Nucleic acid derivatives produced in the small intestine are, to some extent, incorporated directly into tissue nucleic acids (Condon et al. 1970; Smith et al. 1974). The quantitative importance of direct salvage of preformed derivatives is not known although it has been shown in guinea pigs that gastrointestinal mucosa has a very limited capacity for de novo synthesis of purine nucleotides (MacKinnon \& Deller, 1973). Salvage could be particularly important in this tissue which has a reasonably rapid rate of cell proliferation. The value of nucleic acid derivatives as a source of non-specific $\mathbf{N}$ has been suggested (Condon \& Hatfield, I97I) but would only be of value under conditions where non-essential amino acid$\mathbf{N}$ was limiting (Peers, 1977). It has been suggested that the salvage and recycling of nucleic acid $P$ is of prime importance and may explain the development of high pancreatic ribonuclease in ruminants (Barnard, 1969) and results presented by Armstrong \& Hutton (1975) tend to support this view.

The author thanks Dr R. H. Smith for his interest in the work and advice during the preparation of the manuscript; also $\mathrm{Dr} \mathrm{H}$. L. Buttle for the insertion of cannulas, Misses C. Philips and K. Smith for help with the animal experiments and Mr E. S. Griffith for skilled technical assistance. 


\section{REFERENCES}

Anderson, N. G. \& Ladd, F. C. (1962). Biochim. biophys. Acta 55, 275.

Armstrong, D. G. \& Hutton, K. (1975). In Digestion and Metabolism in the Ruminant, pp. 432-447 [I. W. McDonald and A. C. I. Warner, editors]. Armidale: University of New England Publishing Unit.

Badawy, A. M., Campbell, R. M., Cuthbertson, D. P., Fell, F. B. \& Mackie, W. S. (1958), Br. J. Nutr. 12, 367.

Barnard, E. A. (1969). Nature, Lond. 221, 340.

Centar, M. S. \& Behal, F. J. (1966). Archs Biochem. Biophys. I14, 414.

Christman, A. A. (1952). Physiol. Rev. 32, 303.

Coehlo da Silva, J. F., Seeley, R. C., Beever, D. E., Prescott, J. H. D. \& Armstrong, D. J. (1972). Br. J. Nutr. 28, 357.

Coehlo da Silva, J. F., Seeley, R. C., Thomson, D. J., Beever, D. E. \& Armstrong, D. J. (1972). Br. J. Nutr. $28,43$.

Condon, R. J. (1971). Diss. Abstr. int. 32B. 641.

Condon, R. J., Hall, G. \& Hatfield, E. E. (1970). J. anim. Sci. 3r, 1037.

Condon, R. J. \& Hatfield, E. E. (I97I). Fedn Proc. Fedn Am. Socs exp. Biol. 30, 402.

Ellis, W. C. \& Bleichner, K. L. (1969). Fedn Proc. Fedn Am. Socs exp. Biol. 28, 623.

Gregory, M. E. (1954). Br. J. Nutr. 8, 340.

Jackson, T. C., Schelling, G. T., Mitchell, G. E. \& Tucker, R. E. (1976). J. Anim. Sci. 43, 325.

Kaplan, V. A. \& Pobirsky, N. N. (1974). Skh. Biol. 9, 9 I.

McAllan, A. B. \& Smith, R. H. (1969). Br. J. Nutr. 23, 67I.

McAllan, A. B. \& Smith, R. H. (1973). Br. J. Nutr. 29, 331.

McAllan, A. B. \& Smith, R. H. (1974). Br. J. Nutr. 31, 77.

MacKinnon, A. M. \& Deller, D. J. (1973). Biochim. biophys. Acta 319, I.

McMeniman, N. P. (1975). Aspects of nitrogen digestion in the ruminant. PhD Thesis, University of Newcastle upon Tyne.

MacRae, J. C. \& Armstrong, D. G. (1969). Br. J. Nutr. 23, 15.

Morgenstern, S., Flor, R. V., Kaufman, J. H. \& Klein, B. (1966). Clin. Chem. 12, 748.

Peers, D. G. (1977). Proc. Nutr. Soc. 36, 63A.

Portmann, P. (1957). Z. Physiol. Chem. 309, 87.

Smith, R. C., Moussa, N. M. \& Hawkins, G. E. (1974). Br. J. Nutr. 32, 529.

Smith, R. H. \& McAllan, A. B. (1966). Br. J. Nutr. 20, 703.

Smith, R. H. \& McAllan, A. B. (1971). Br. J. Nutr. 25, 181 .

Smith, R. H., McAllan, A. B., Hewitt, D. \& Lewis, P. L. (1978). J. agric. Sci., Camb. 90, 557.

Thill, N., Francois, E., Thewis, A. \& Thielemans, M.-F. (1978). Ann. Zootech. 27, 363.

Toofanian, F. \& Teshfam, M. (1978). Res. Vet. Sci. 24, 382.

Topps, J. H. \& Elliott, R. C. (1965). Nature, Lond. 205, 498.

Williams, A. P. \& Smith, R. H. (1974). Br. J. Nutr. 32, 42 1.

Wilson, D. W. \& Wilson, H. C. (1962). J. biol. Chem. 237, 1643 .

Wilson, T. H. \& Wilson, D. W. (1958). J. biol. Chem. 233, I 544 .

Young, E. G. \& Conway, C. F. (1942). J. biol. Chem. 142, 839.

Zittle, C. A. (1946). J. biol. Chem. 166, 499. 